\title{
VALENTINE ALLORGE (1888-1977). SU CONTRIBUCION A LA BRIOFLORA ESPAÑOLA
}

\author{
C. CASAS DE PUIG (*)
}

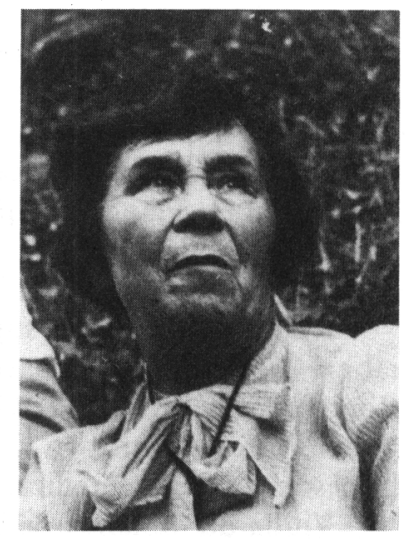

\section{RESUMEN:}

Breve resumen de su biogratía seguida de un comentario sobre sus trabajos realizados en España, así como sus relaciones con los briólogos españoles.

SUMMARY:

A short account of her biography, followed by her work carried out in Spain, together with her relations with Spanish bryologists.

Con verdadera emoción inicio esta sesión de briología recordando a una respetable amiga muy querida, a la que por sus méritos científicos y humanos, la comisión organizadora de este Simposio ha accedido le sea dedicada esta sesión para rendirle el merecido homenaje.

El grupo español de briología, nacido y desarrollado cuando la Sra. Allorge, debido a su avanzada edad, ya no venía a España, recibió en todo momento el aliento y la ayuda científica de esta dama que conocía y amaba nuestro país a través de su paisaje, su flora, los pueblos y sus costumbres. Sus estancias en Es- 
paña, su trato con los botanicos españoles, sus trabajos sobre taxonomía y distribución geográfica de las especies muscinales en España, han contribuído en gran manera al avance en el conocimiento de la briología española. Por estas razones creemos que esta sesión, la primera que celebramos después de su fallecimiento, es el momento más oportuno para manifestar públicamente el merecido agradecimiento que le debemos.

La biografía de la Sra. V. Allorge y sus actividades científicas, sus viajes a España, sus trabajos y su competencia son bien conocidos de los botánicos españoles, así como su gran afabilidad, su encantadora sencillez y su buen hacer que le captaron la simpatía, el respeto y la admiración de cuantos la conocieron.

No obstante, deseo exponer en un breve resumen los rasgos más interesantes de su labor científica en relación con los estudios que se refieren a nuestro país.

Nacida Valentine Sélitzky el año 1888 en Jouravlevska (Rusia), vivió desde muy joven en Francia, su patria adoptiva, adquiriendo finalmente la nacionalidad francesa. Se identificó con su patria de adopción pero recordaba con nostalgia su patria de origen.

Realizó sus estudios superiores en Lausana. Después, preparó su tesis doctoral en Ciencias Naturales, sobre Anatomía Vegetal, bajo la dirección de Gaston Bonnier en la Facultad de Ciencias de París. Durante varios años fue colaboradora del Profesor Perrot en la Facultad de Farmacia de París, publicando algún trabajo sobre plantas medicinales.

Viuda del botánico C.L. Gautin contrajo segundas nupcias en 1920 con P. Allorge. Colaboró en los trabajos de su esposo y le acompañó en sus viajes a España, Portugal, las Azores, Guadalupe y Martinica.

En sus primeros viajes a España en 1925 conocieron al Dr. A. Casares Gil, que entonces se hallaba en La Coruña. La Sra. Allorge recordaba con afecto la amistad que les unió a nuestro gran briólogo. Ella fue el nexo, en el tiempo, entre Casares y los briólogos actuales que no le conocimos personalmente. Ella narraba pormenores y anécdotas de tan brillante briólogo español fallecido en el momento de la máxima plenitud en su trabajo. Guardaba una gran admiración a su talento y a su personalidad; elogiaba su competencia científica, su sencillez y su gran humanidad. En varias ocasiones, Casares Gil acompañó a a mbos esposos para mostrarles las localidades gallegas donde había descubierto la presencia de especies interesantes.

Después del fallecimiento de Casares en 1929, la mayor parte de los estudios briológicos realizados con rigor científico los debemos a los esposos Allorge. Hasta 1941 vinieron a España periódicamente, recolectaron en numerosas localidades y visitaron casi la totalidad de las provincias españolas. Los numerosos trabajos publicados son el mejor testimonio de su paso por la Península.

Las privaciones y las inquietudes que sufrieron durante la segunda guerra mundial minaron ya la débil salud de P. Allorge; resultaron inútiles los esfuerzos de la ciencia y los cuidados de la esposa, P. Allorge falleció el 21 de enero de 1944.

V. Allorge sucedió a su esposo en la dirección de la Revue Bryologique et Lichénologique, cargo que ostentó hasta el último momento de su vida. Terminó y publicó los trabajos póstumos de su esposo y continuó realizando viajes por España. Se relacionó con los botánicos españoles especialmente P. Font i Quer, 
A. de Bolós, P. Seró y más tarde con T.M. Losa España y S. Rivas Goday.

Estuvo en Barcelona en julio de 1952 invitada por el Director del Instituto Botánico, Dr. A. de Bolós, para dirigir un cursillo práctico de briología. Un reducido grupo de botánicos catalanes nos interesábamos por esta rama de la Botánica y sus enseñanzas fueron muy útiles, me atrevería a decir definitivas, en el sentido de no abandonar ya el interés por esta especialidad y hacerla el objeto de nuestra principal dedicación investigadora. Con ella recorrimos, en aquella ocasión, los montes de Prades, el vale de Nuria y las montañas más próximas a Olot.

En 1953 volvía a Barcelona, punto de partida de la décima I.P.E. Recorrio durante un mes parte del norte, centro y sur de España. En septiembre de 1954 nos reunimos en Luchon con motivo del II Congreso de Estudios Pirenaicos y durante la excursión dirigida por $\mathrm{H}$. Gaussen al valle de Arán hicimos unas recolecciones en Les y en Port de la Bonaigua. En julio de 1955 volvimos a reunirnos con ella en el Pirineo, expresamente invitadas, junto con el Dr. M. Losa España, por el Prof. H. Gaussen. En esta ocasión visitamos el valle de Ordesa, Benasque, Castanesa, Pont de Suert, Valles de Boí y Roda de Isaba, en cuyas proximidades encontró Zygodon forsteri.

En 1956 pasó otra vez por Barcelona y me rogó la acompañara a alguna parte de Cataluña para hacer alguna prospección muscinal. Entonces había iniciado un estudio de la flora briológica del Cap de Creus y me pareció oportuno estar allí con ella a lgunos días. Fue entonces cuando descubrió en los rellanos de rocas silíceas húmedas cerca del Port de la Selva la Oedipodiella australis. Posteriormente identificó Funaria mustafae de Cadaqués.

En abril de 1957 el profesor Rivas Goday organizó una excursión escolar a Andalucía a la que nos invitó junto con el Dr. Losa España. La Sra. Allorge siempre estaba dispuesta a venir a España y aceptó la invitación muy complacida. Con ella recolectamos en Sierra Morena, Despeñaperros, Javalcuz, Aguadulce y en el Cabo de Gata. El resultado espectacular de aquella excursión fue el hallazgo de Gigaspermum mouretii.

Deseaba ir a Algeciras para recordar y reconocer de nuevo localidades visitadas en 1934 con su esposo. Coincidimos allí con ella en octubre de 1959. Me mostró localidades próximas a Algeciras donde hicimos interesantes recolecciones. En el bosque de Almoraima al borde del río Guadarranque encontró Funaria pulchella.

En mayo de 1960 se inscribió a la excursión de la Asociación Internacional de Fitosociología dirigida por R. Tüxen. Nos encontramos en la parte española del Pirineo: Ordesa, Jaca, San Juan de la Peña, Valle de Ansó y el Roncal.

Además de los trabajos póstumos de P. Allorge, que ordenó y terminó para su publicación, colaboró en la confección de la "Briotheca Iberica", exsiccata que cuenta con cinco series de cincuenta especies cada una, de las cuales la primera, segunda y quinta corresponden a España y las restantes a Portugal.

Redactó otras notas y trabajos, resultado de sus numerosas excursiones por España. Con su esposo, desde 1925 hicieron hasta 26 viajes a España y Portugal. Sus trabajos publicados a partir de 1918 versan sobre anatomía vegetal y plantas medicinales. A partir de 1938 sus numerosos trabajos, en total más de 60, se dedican ya exclusivamente al estudio de los briófitos, algunos de estos trabajos herhos en colaboración con su esposo, Mme. S. Jovet-Ast, cuya estimada colabora- 
ción perduró hasta su fallecimiento, Richards, Seró y Casas.

Su compañía en las excursiones era sumamente agradable y provechosa. Su conversación siempre cordial y amable. Excelente conocedora de las especies muscinales y de su ecología, sus enseñanzas en el campo y en el laboratorio fueron muy útiles. Su tenacidad, el rigor científico, su amor a la verdad eran ejemplares.

Siempre la hallábamos presta a atendernos, sea personalmente en el Museo de Criptogamia de París, cuando nos desplazábamos allí con todas nuestras dudas e indecisiones, o por medio de la correspondencia epistolar. Sentía una predilección especial hacia la brioflora española que le era familiar como si se tratara de la de su propio país, no en vano había venido muchas veces, con su esposo primero y sola después, y había recolectado en muchas localidades, de tal manera, que ahora es difícil hacer el estudio de cualquier zona de España sin tener necesidad de citar sus trabajos entre la bibliografía.

De su extensa bibliografía extraemos los siguientes trabajos referentes a la briología española:

-1943-1944- Au sujet du Sphagnum molle Sull. en Espagne et de sa varieté limbatum Wst. dans les Landes. Rev. Bryol. Lichénol. 14: 163-167. Paris.

-1955- Catalogue préliminarire des Muscinées du Pays basque française et espagnol. Rev. Bryol. Lichénol. 24: 96-131; 248-333. Paris.

-1957-Zygodon Forsteri (Dicks.) Mitt. nouveau pour l'Espagne. Rev. Bryol. Lichénol. 26: 8485.

Paris.

-1960- A propos d’un Funaria nouveau pour la Péninsule Ibérique. Rev. Bryol. Lichénol. 29: 110-117. Paris.

-1970- Une localité nouvelle pour le Sphagnum pylaisii Brid. en Espagne. Rev. Bryol. Lichénol. 37: 685-688. Paris.

-1976- Localités espagnoles de Funaria pulchella Philibert. Rev. Bryol. Lichénol. 42: 637-639. Paris.

- et Allorge, P. -1930- D. Antonio Casares Gil (1872-1929). Rev. Bryol. Lichénol, nouv. sér. 3: 1-4. Paris.

- et ALLORGE, P. - 1941- Les ravins a Fougeres de la corniche vasco-cantabrique. Bull. Soc. Bot. France 88: 92-111 2 pl. Paris.

- et ALLORGE, P. - 1945- La végétation et les groupements muscinaux des montagnes d'Algésiras. Mem. Mus. Nac. Hist. Nat. 21: 85-116. Paris.

- et ALLORGE, P. - 1946- Notes sur la flore bryologique de la Péninsule Ibérique. X. Muscinées du Sud et de l'Est de l'Espagne. Rev. Bryol. Lichénol. 15: 172-200. Paris.

- et ALLORGE, P. - 1950- Les éléments méditerranéens dans la Bryotlore du Pays Basque. Rev. Bryol. Lichénol. 19: 229-233. Paris.

- et CASAS, C. -1958- Contribution a la flore bryologique de l'Espagne. Rev. Bryol. Lichénol. 27: 55-65. Paris.

- et CASAS, C. - 1962- Au sujet des Bryophytes récoltées au cours de l'excursion de l'Association Internationale de Phytosociologie dans les Pyrénées franco-espagnoles, (22-29 mai 1960). Rev. Bryol. Lichénol. 31: 213-238. Paris.

- y CASAS, C. -1962- Contribution a la flore bryologique du Val d'Aran. Actas tercer Congr. Intern. Est. Pirenaicos 3: 163-177. Zaragoza.

- y CASAS, C. -1968- Contribución al estudio de la flora briológica catalana. II. Briótitos del llano de Olot y montañas próximas. Collect. Bot. 7: 47-68. Barcelona.

- y CASAS, C. -1976- Contribución al estudio de la flora briológica catalana. III. Músgos y Hepáticas del Valle de Nuria. Collect. Bot. 10: 13-28. Barcelona.

- CASAS, C. y SERO, P. -1962-Contribución al estudio de la flora briológica catalana. I. Briófitos de los montes de Prades. Collect. Bot. 6: 331-248. Barcelona. 
- et JOVET-AST, S. - 1958- La distribution des Marchantiales dans la Péninsule Ibérique et au Maroc. P. Inst. Biol. Apl. (Simposio de Biogeogratia Ibérica) 27: 129-145. Barcelona.

- and RICHARDS, P.W. -1956- Bryophytes collected in Spain during the Tenth I.P.E. in 1953. Verott. Geobotanisches Institut Rabel in Zürich 31: 250-267. Bern.

Se llevó consigo una última ilusión sin verla realizaba. Desde mucho tiempo proyectábamos con ella hacer un catálogo de la brioflora española. Pocos días antes de su fallecimiento, Esther Fuertes estuvo en París para ayudarle a ordenar sus datos que debíamos integrarlos en los nuestros. Un desgraciado accidente impidió que se terminara la ordenación de sus fichas y en aquel 24 de diciembre último, casi a los 90 años de edad, se terminaba todo para ella. Posteriormente hemos obtenido los datos que deseaba entregarnos. Agradecemos a Mme. S. Jovet-Ast todas las atenciones recibidas.

El recuerdo de su presencia y su ejemplo nos alentarán para continuar con dignidad y rigor este catálogo, última ilusión de su vida. Descanse en paz nuestra amiga V. Allorge. 